\title{
Elevated antistreptolysin O titer is closely related to cardiac mitral insufficiency in untreated patients with Takayasu arteritis
}

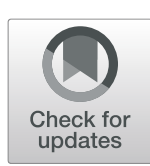

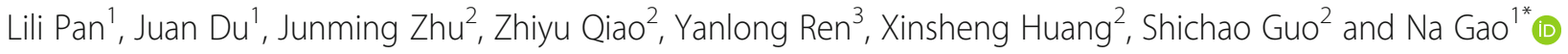

\begin{abstract}
Background: The etiology of Takayasu arteritis (TA) is unknown; however, a possible relationship between streptococcal infection and TA has been proposed. This study aimed to identify the clinical features and cardiac valvular involvement in untreated TA patients with an elevated antistreptolysin O (ASO) titer.

Methods: In this retrospective study, the clinical characteristics and features of valvular involvement were compared in TA patients with or without an elevated ASO titer.

Results: Of the 74 untreated TA patients, 13 patients were found have elevated ASO titers (17.6\%). Mitral insufficiency was the most common in patients with elevated ASO $(69.2 \%, 9 / 13)$, followed by aortic valve insufficiency $(46.2 \%, 5 / 13)$ and tricuspid insufficiency $(46.2 \%, 5 / 13)$, which were no significantly different than that in normal ASO group. The proportions of moderate to severe mitral (30.8\% vs $1.6 \%, p=0.000)$ and tricuspid valve $(15.4 \%$ vs $1.64 \%, p=0.023)$ insufficiency in the ASO positive group were significantly higher than those in the ASO negative group. The odds of mitral regurgitation in patients with elevated ASO titers were 3.9 times higher than those in the group with normal ASO titers ( $p=0.053, \mathrm{OR}=3.929,95 \%$ confidence interval [Cl]: 0.983-15.694). Furthermore, the risk of moderate to severe mitral insufficiency in patients with elevated ASO titers was 41.6 times higher than that in patients with normal ASO titers ( $p=0.002, \mathrm{OR}=41.600,95 \% \mathrm{Cl}: 3.867-447.559)$.
\end{abstract}

Conclusions: An increase in ASO titer is related to valvular involvement in TA and is closely linked to mitral insufficiency.

Keywords: Takayasu arteritis, Anti-streptolysin O, Mitral insufficiency

\section{Key-points}

- Mitral insufficiency was common in TA patients with elevated ASO.

- There was a positive correlation between the titer of ASO and TA disease activity.

- Elevated ASO was risk factor to mitral involvement in untreated TA patients.

\section{Background}

Takayasu arteritis (TA) is a type of chronic, systemic vessel vasculitis that mainly involves the aorta and its major branches, and is more common in young women

\footnotetext{
* Correspondence: gaona1230@163.com

'Department of Rheumatology and Immunology, Beijing Anzhen Hospital, Capital Medical University, 2 Anzhen Road, Chaoyang District, Beijing, China Full list of author information is available at the end of the article
}

of Asian descent [1]. Granulomatous inflammation in the media and adventitia is the pathological characteristic of TA, which results in fibrosis of large vessel walls, causing destruction of the elastic lamina and media [2]. Although the etiology of TA is not clear, several studies may have indicated a link with an antigen-driven, immune-mediated process [3, 4]. Streptococcal antigen is considered to play a important role in the autoimmune reaction of streptococcal infection-related disorders [5] and had been reported that TA sera reacted with streptococcal antigens [6]. The most widely used clinical antibody assays involve antistreptolysin $\mathrm{O}$ (ASO), which is valuable in patients with possible group A $\beta$-hemolytic streptococcal infections. Both TA and rheumatic fever (RF) could present with cardiac manifestations [7] and cause valvular disorders, resulting in systemic manifestations and making the diagnosis difficult 
[8]. Some reported cases of TA were diagnosed a few years after an initial diagnosis of RF $[9,10]$. Cardiac involvement is the key determinant of morbidity and mortality in both TA and RF. They share similar clinical and epidemiological characteristics [11]. The incidence of cardiac valvular abnormalities in patients with TA is 7.0-36.7\% [12]. Previous researchers have found a poor prognosis of TA with cardiac valvular involvement, which should be taken into consideration $[13,14]$.

Therefore, this study aimed to investigate the clinical features of cardiac valvular involvement in TA patients with positive ASO titers and to analyze the correlation between ASO titers and untreated TA disease activity.

\section{Methods}

\section{Patients}

This is a retrospective study, approved by Capital Medical University affiliated Beijing Anzhen Hospital Ethics Committee (approval number: 2018054X). Seventy-four consecutive untreated TA patients were enrolled, according to the criteria for classifying TA developed by the American College of Rheumatology in 1990 [15]. In total, 119 patients (74 were untreated) diagnosed with TA from January 2012 to December 2017 in Beijing Anzhen Hospital were recruited. We reviewed the records including demographic characteristics, clinical manifestations, laboratory tests, and imaging findings. Because acute RF affects cardiac valves, it was ruled out in the diagnosis of TA; therefore, there were no acute RF patients in our subjects. A modified version of Kerr's criteria (Kerr score) [16] and the Indian Takayasu Clinical Activity Score (ITAS) [17] were used to assess TA disease activity. The differences in the clinical characteristics and features of valvular involvement were compared in patients with or without elevated ASO.

\section{Laboratory test}

Four milliliters of venous blood were collected and the serum was isolated. An automatic biochemical analyzer (7600-120, Hitachi, Tokyo, Japan) was used to analyze the serum parameters. After the patients were diagnosed with TA, their serum was collected and tested by the hospital laboratory department, and the results were reported. The ASO titer was determined by immune transmission turbidimetry (DiaSys Diagnostic Systems, Shanghai, China) with ASO $\leq 200 \mathrm{IU} / \mathrm{mL}$ as negative and ASO $>200 \mathrm{IU} / \mathrm{mL}$ as positive. The erythrocyte sedimentation rate (ESR) was detected by the modified Westergren method.

\section{Angiographic features and echocardiogram}

Magnetic resonance angiography, computed tomography angiography, and Doppler ultrasound were used to evaluate the thoracic and abdominal aorta and aortic branches. The lesions were classified according to the 1996 Numano classification [18]. Echocardiograms were obtained with a 5-MHZ ultrasound probe (EPIQ 7C, Philips, the Netherlands) to evaluate the cardiac structure and function following published guidelines [19-21]. The severity of mitral and tricuspid regurgitation was graded by using quantitative values similar to those for aortic regurgitation according to the American Society of Echocardiography recommendations [22].

\section{Statistical analysis}

According to the normality, numerical data were expressed as quartiles or means \pm standard error. And unpaired $t$ - test or Mann-Whitney $\mathrm{U}$ test were used to determine the differences between TA patients with positive and negative ASO. For qualitative parameters, $X^{2}$ test was used assessed the differences between two groups. Variables including ASO, ESR, IgA, IgG, Kerr Score, complement 3 (C3), and ITAS were computed to a multivariate backward stepwise logistic regression analysis ( $p=0.05$ entry and $p=0.10$ removal criteria) to predict the independent risk factors for the valvular involvement in TA patients. All $p$-values were two-tailed and $p<0.05$ was interpreted as statistical significance. SPSS 16.0 statistical software (SPSS Inc., Chicago, IL, USA) was used for all the statistical analyses.

\section{Results}

\section{General characteristic of untreated TA patients with positive ASO}

There were 60 females (81.1\%) and 14 males (18.9\%). The median duraion of the disease was $48(6.0,144.0)$ months. Thirteen patients $(17.6 \%)$ had a positive ASO titer $(\geq 200 \mathrm{IU} / \mathrm{ml})$, including 11 females $(84.6 \%)$ and two males (15.4\%). The average age of disease onset was 29.5 years (range 19.0-48.0) and the disease course ranged from 1 month to 3 years, with a median course of 6 months. The ASO titer ranged from 226 to $991 \mathrm{IU} / \mathrm{ml}$. The most common angiographic type was Numano type $\mathrm{V}(30.8 \%, 4 / 13)$, followed by type I $(23.1 \%, 3 / 13)$ and type IIb $(23.1 \%, 3 / 13)$. In three patients $(23.1 \%)$, the disease was complicated with pulmonary artery involvement and in one (7.7\%), with coronary artery involvement (Table 1).

\section{Clinical features and angiographic manifestation in untreated TA patients with positive ASO}

We compared the clinical manifestations of TA patients with positive or negative ASO. There were no significant differences in age, sex, duration of disease, and body mass index (BMI). There were also no significant differences in the clinical features and angiographic findings between the two groups. No significant difference in 
Table 1 General characteristics of untreated TA patients with elevated ASO titer

\begin{tabular}{|c|c|c|c|c|c|}
\hline No & Disease duration (month) & Symptoms & Numano Type & Features of valvular involvement & $\begin{array}{l}\text { ASO titer } \\
(\mathrm{IU} / \mathrm{ml})\end{array}$ \\
\hline 1 & 1 & Left upper limb weakness & $11 \mathrm{~b}$ & Mild mitral insufficiency & 276 \\
\hline 2 & 120 & Dizziness & $\mathrm{V}, \mathrm{P}+$ & $\begin{array}{l}\text { Mild aortic insufficiency, mitral valve thickening, } \\
\text { calcification and adhesion, moderate mitral stenosis } \\
\text { and insufficiency }\end{array}$ & 980 \\
\hline 3 & 144 & Dizziness, Fatigue & V & $\begin{array}{l}\text { Mild aortic insufficiency, mitral valve calcification } \\
\text { and prolapse, moderate mitral insufficiency, mild } \\
\text { tricuspid insufficiency }\end{array}$ & 398 \\
\hline 4 & 5 & Chest tightness & v & $\begin{array}{l}\text { Mitral annulus dilatation and valve edge thickening, } \\
\text { severe mitral insufficiency, moderate tricuspid } \\
\text { insufficiency, pulmonary hypertension (Systolic } \\
\text { pulmonary artery pressure: } 70 \mathrm{mmHg} \text { ) }\end{array}$ & 580 \\
\hline 5 & 12 & Double upper limb weakness & । & $\begin{array}{l}\text { Mild aortic insufficiency, mitral valve thickening, } \\
\text { mild mitral insufficiency }\end{array}$ & 709 \\
\hline 6 & 6 & Headache, fever, Fatigue & IV & None & 560 \\
\hline 7 & 1 & Chest tightness, Palpitations & । & None & 269 \\
\hline 8 & 180 & Chest tightness & V & $\begin{array}{l}\text { Severe mitral insufficiency, mild tricuspid insufficiency, } \\
\text { mild pulmonary insufficiency, pulmonary hypertension } \\
\text { (Systolic pulmonary artery pressure: } 50 \mathrm{mmHg} \text { ) }\end{array}$ & 226 \\
\hline 9 & 1 & Headache & I & $\begin{array}{l}\text { Aortic valve edge thickening, mild mitral insufficiency, } \\
\text { mild tricuspid insufficiency }\end{array}$ & 991 \\
\hline 10 & 48 & $\begin{array}{l}\text { Left upper limb weakness, } \\
\text { Palpitations }\end{array}$ & $\| \mathrm{ll}, \mathrm{P}+$ & $\begin{array}{l}\text { Aortic valve edge thickening, severe aortic insufficiency, } \\
\text { mild mitral insufficiency, severe tricuspid insufficiency, }\end{array}$ & 274 \\
\hline 11 & 360 & Fatigue & III & None & 279 \\
\hline 12 & 3 & Chest tightness & $\mathrm{llb}, \mathrm{P}+\mathrm{C}+$ & $\begin{array}{l}\text { Aortic valve edge thickening, moderate aortic insufficiency, } \\
\text { mild mitral insufficiency, mild tricuspid insufficiency, } \\
\text { pulmonary hypertension (Systolic pulmonary artery } \\
\text { pressure: } 59 \mathrm{mmHg} \text { ) }\end{array}$ & 268 \\
\hline 13 & 60 & Double upper limb weakness & $\| b$ & Mild aortic valve insufficiency & 544 \\
\hline
\end{tabular}

pulmonary artery and coronary artery involvement was observed, no atrial fibrillation was found in TA patients with valvular involvement (Table 2).

\section{Comparison of laboratory values and disease activity between untreated TA patients with positive or negative ASO titers}

We compared the laboratory parameters and disease activity indexes of the two groups of patients. The results showed that the level of serum immunoglobulin (Ig) G in patients with positive ASO was significantly higher than that in patients with negative ASO (16.6 \pm 4.1 vs $12.9 \pm 3.7, p=0.002)$. There was no significant difference in other parameters such as blood routine, liver function, kidney function, Ig A, IgM, complement 3 (C3), and complement 4 (C4). No significant difference in the disease activity index such as ESR, C-reactive protein (CRP), Kerr score and ITAS was found between the two groups (Table 3 ).

We analyzed the correlation between ASO titer and the indexes of disease activity. The results showed that the titer of ASO was positively correlated with ESR ( $r=$ $0.291, p=0.040)$, Kerr score $(r=0.286, p=0.044)$, ITAS $(r=0.295, p=0.037)$, IgG $(r=0.502, p=0.000)$, and C3 $(r=0.285, p=0.047)$. There was no correlation between ASO titer and CRP, IgA, IgM, and C4.

\section{Cardiac valvular involvement in untreated TA patients with positive ASO}

Of the patients with positive ASO, 76.9\% (10/13) had abnormal valvular findings. The proportion with abnormal valvular findings in patients with negative ASO was $65.6 \%(40 / 61)$, which was not significantly different. In each group, one case showed mitral stenosis and the others were valvular insufficiency. Mitral valve insufficiency was most common in patients with elevated ASO, accounting for $69.2 \%$ (9/13) (valve thickening in three patients, calcification in two, adhesion in one, and prolapse in one), which was not statistically significant compared with patients with normal ASO. Aortic valve insufficiency $(46.2 \%, 5 / 13)$ and tricuspid valve insufficiency $(46.2 \%, 5 / 13)$ were not significantly different between the two groups. One patient in each group had pulmonary valve insufficiency, one positive ASO patient showed stenosis complicated with insufficiency of the mitral valve, which was not significantly different 
Table 2 Clinical and lab features of untreated TA patients with positive or negative ASO

\begin{tabular}{|c|c|c|c|}
\hline & $\begin{array}{l}\text { ASO positive } \\
n=13\end{array}$ & $\begin{array}{l}\text { ASO negative } \\
n=61\end{array}$ & $P$-Value \\
\hline Female, n(\%) & $11(84.6)$ & 49 (78.7) & 0.720 \\
\hline Age of onset (year) & $29.5 \pm 10.0$ & $33.5 \pm 12.5$ & 0.281 \\
\hline Disease duration (month) & $6.0(1.0,102.0)$ & $48.0(12.0,168.0)$ & 0.081 \\
\hline $\mathrm{BMI}\left(\mathrm{kg} / \mathrm{m}^{2}\right)$ & $23.3 \pm 3.5$ & $22.8 \pm 3.5$ & 0.641 \\
\hline Arteriosclerosis, n(\%) & $3(23.1)$ & $30(49.2)$ & 0.086 \\
\hline Hypertension, n(\%) & $5(38.5)$ & $13(21.3)$ & 0.191 \\
\hline T2DM, n(\%) & $0(0.0)$ & $4(6.6)$ & 0.342 \\
\hline Smoker, n(\%) & $2(15.4)$ & $11(18.0)$ & 0.820 \\
\hline Heart failure, n(\%) & $4(30.8)$ & $9(14.8)$ & 0.168 \\
\hline $\mathrm{AF}, \mathrm{n}(\%)$ & $0(0.0)$ & $0(0.0)$ & - \\
\hline Aneurysms, n(\%) & $3(23.1)$ & $13(21.3)$ & 0.966 \\
\hline Dizziness, n(\%) & $7(53.9)$ & $27(44.3)$ & 0.529 \\
\hline Headache, n(\%) & $2(15.4)$ & $11(18.0)$ & 0.820 \\
\hline Asymmetry in $\mathrm{BP}, \mathrm{n}(\%)$ & $6(46.2)$ & $23(37.7)$ & 0.571 \\
\hline Pulseless, n(\%) & $4(30.8)$ & $13(21.3)$ & 0.462 \\
\hline Chest tightness, n(\%) & $5(38.5)$ & $17(27.9)$ & 0.448 \\
\hline Chest pain, $n(\%)$ & $2(15.4)$ & 15 (24.6) & 0.474 \\
\hline Palpitations, n(\%) & $3(23.1)$ & $4(6.6)$ & 0.065 \\
\hline Carotidynia, n(\%) & $1(7.7)$ & $4(6.6)$ & 0.882 \\
\hline Erythema nodosum, n(\%) & $1(7.7)$ & $1(1.6)$ & 0.222 \\
\hline Blurred vision, n(\%) & $0(0.0)$ & $4(6.6)$ & 0.342 \\
\hline Fever, n(\%) & $3(23.1)$ & $9(14.8)$ & 0.460 \\
\hline Fatigue, n(\%) & $4(30.8)$ & $14(23.0)$ & 0.551 \\
\hline Weight loss, n(\%) & $2(15.4)$ & $3(4.9)$ & 0.172 \\
\hline \multicolumn{4}{|l|}{ Numano Type } \\
\hline I & $3(23.1)$ & $16(26.2)$ & 0.086 \\
\hline Ila & $1(7.7)$ & $3(7.7)$ & 0.688 \\
\hline$\| \mathrm{b}$ & $3(23.1)$ & $9(14.8)$ & 0.460 \\
\hline III & $1(7.7)$ & $4(6.6)$ & 0.882 \\
\hline IV & $1(7.7)$ & $1(1.6)$ & 0.222 \\
\hline V & $4(30.8)$ & $25(41.0)$ & 0.493 \\
\hline $\mathrm{P}+$ & $3(23.1)$ & $7(11.5)$ & 0.267 \\
\hline $\mathrm{C}+$ & $1(7.7)$ & $14(23.0)$ & 0.214 \\
\hline
\end{tabular}

Note: $B M I$ Body mass index; T2DM type 2 diabetes mellitus; $A F$ atrial fibrillation $P+$ pulmonary artery involvement; $C+$ coronary artery involvement

between groups. The incidence of multiple valve involvement in the positive ASO group was $61.5 \%$ (8/13), which was higher than that in the negative ASO group (34.4\%, $21 / 61)$, although there was no significant difference ( $p=$ 0.069). Single valve involvement was found in two cases (15.4\%) in the ASO positive group and 19 cases (31.2\%) in the ASO negative group, with no significant difference.

The proportion of moderate to severe mitral insufficiency in the ASO positive group was significantly
Table 3 Laboratory parameters and disease activity of untreated TA patients with positive or negative ASO

\begin{tabular}{|c|c|c|c|}
\hline & $\begin{array}{l}\text { ASO positive } \\
n=13\end{array}$ & $\begin{array}{l}\text { ASO negative } \\
n=61\end{array}$ & $P$-Value \\
\hline$\overline{W B C}\left(10^{9} / \mathrm{L}\right)$ & $7.0 \pm 1.5$ & $7.3 \pm 2.2$ & 0.643 \\
\hline $\operatorname{NE}\left(10^{9} / L\right)$ & $4.7 \pm 1.4$ & $4.7+1.7$ & 0.979 \\
\hline $\operatorname{LY}\left(10^{9} / \mathrm{L}\right)$ & $1.9 \pm 0.6$ & $2.1 \pm 0.8$ & 0.391 \\
\hline $\operatorname{RBC}\left(10^{12} / \mathrm{L}\right)$ & $4.51 \pm 0.41$ & $4.5 \pm 0.5$ & 0.812 \\
\hline $\mathrm{Hb}(\mathrm{g} / \mathrm{L})$ & $122.8 \pm 21.9$ & $124.2 \pm 19.3$ & 0.809 \\
\hline $\operatorname{PLT}\left(10^{9} / \mathrm{L}\right)$ & $278.6 \pm 107.2$ & $265.4 \pm 90.1$ & 0.645 \\
\hline $\operatorname{ALT}(\mathrm{U} / \mathrm{L})$ & $13.7 \pm 10.5$ & $18.2 \pm 14.3$ & 0.289 \\
\hline $\mathrm{Cr}(\mu \mathrm{mol} / \mathrm{l})$ & $63.1 \pm 12.8$ & $61.2 \pm 31.1$ & 0.833 \\
\hline GLU (mmol/l) & $5.0 \pm 0.6$ & $5.2 \pm 1.1$ & 0.612 \\
\hline $\mathrm{HCY}(\mu \mathrm{mol} / \mathrm{l})$ & $11.5 \pm 3.5$ & $13.9 \pm 9.5$ & 0.388 \\
\hline $\mathrm{RF}(\mathrm{IU} / \mathrm{ml})$ & $6.5(4.0,10.6)$ & $5.2(3.1,11.7)$ & 0.222 \\
\hline IL-6 (pg/ml) & $16.2(3.3,29.4)$ & $5.1(2.3,12.5)$ & 0.157 \\
\hline TNF-a (pg/ml) & $9.6(5.8,22.6)$ & $20.3(7.7,48.7)$ & 0.210 \\
\hline $\lg A(g / L)$ & $3.2 \pm 1.4$ & $2.5 \pm 1.3$ & 0.086 \\
\hline $\lg G(g / L)$ & $16.6 \pm 4.1$ & $12.9 \pm 3.7$ & 0.002 \\
\hline $\operatorname{lgM}(g / L)$ & $1.5 \pm 0.6$ & $1.4 \pm 1.0$ & 0.823 \\
\hline $\lg E(g / L)$ & $35.6(14.3,176.7)$ & $17.0(9.7,87.3)$ & 0.151 \\
\hline C3 (g/L) & $1.3 \pm 0.3$ & $1.2 \pm 0.2$ & 0.188 \\
\hline C4 (g/L) & $0.2 \pm 0.1$ & $0.2 \pm 0.1$ & 0.657 \\
\hline ESR (mm/1 h) & $23.0(9.0,72.0)$ & $18.0(8.0,39.0)$ & 0.352 \\
\hline CRP (mg/L) & $4.5(1.8,23.6)$ & $2.2(0.4,21.5)$ & 0.334 \\
\hline Kerr Score & $2.5 \pm 0.7$ & $2.4 \pm 0.7$ & 0.484 \\
\hline ITAS & $8.9 \pm 6.0$ & $8.2 \pm 4.8$ & 0.682 \\
\hline
\end{tabular}

Note: $W B C$ white blood cell; $L Y$ lymphocyte; $N E$ neutrophil; $P L T$ platelet; $R B C$ red blood cell; $H b$ hemoglobin; $A L T$ alanine aminotransferase; $\mathrm{Cr}$ creatinine; GLU Glucose; $H C Y$ homocysteine; $R F$ rheumatoid factor; IL interleukin; TNF tumor necrosis factor; Ig immunoglobulin; C3 complement 3; C4 complement 4; ESR erythrocyte sedimentation rate; $C R P$ C-reactive protein

higher than that in the ASO negative group (30.8\% vs $1.6 \%, p=0.000)$. There was no significant difference between the two groups in mild mitral valve insufficiency (38.5\% vs $45.9 \%, p=0.624$ ). Two patients in the positive ASO group and one in the negative ASO group had moderate to severe tricuspid insufficiency; the difference was statistically significant $(15.4 \%$ vs $1.6 \%, p=0.023)$, there was no significant difference between the two groups in mild tricuspid insufficiency $(30.8 \%$ vs $27.9 \%$, $p=0.833$ ). There was no significant difference in aortic insufficiency between the two groups (Table 4).

We further analyzed the features of transesophageal echocardiography between the two groups in TA patients with valvular lesions. We found that $50 \%$ of the patients with elevated ASO had valve thickening (5/10), including 3 patients with aortic valve and 2 patients with mitral valve, which were significantly higher than those in ASO negative group $(10.0 \%, 4 / 40)$ (3 patients with aortic valve and 1 patient with mitral valve) $(p=0.003)$. 
Table 4 Features of cardiac valvular involvement of untreated TA patients with positive or negative ASO

\begin{tabular}{llll}
\hline Valvular involvement & ASO positive & ASO negative \\
$n=61$ & P-Value \\
\hline Total, $\mathrm{n}(\%)$ & $10(76.9)$ & $40(65.6)$ & 0.427 \\
Aortic Valve insufficiency, $\mathrm{n}(\%)$ & $6(46.2)$ & $24(39.3)$ & $18(29.5)$ \\
$\quad$ Mild & $4(30.8)$ & $6(9.8)$ & 0.650 \\
$\quad$ Medium to severe & $2(15.4)$ & $29(47.5)$ & 0.828 \\
Mitral valve insufficiency, $\mathrm{n}(\%)$ & $9(69.2)$ & $28(45.9)$ & 0.559 \\
$\quad$ Mild & $5(38.5)$ & $1(1.6)$ & 0.155 \\
$\quad$ Medium to severe & $4(30.8)$ & $1(1.6)$ & 0.624 \\
Mitral valve stenosis, $\mathrm{n}(\%)$ & $1(7.7)$ & $16(26.2)$ & 0.000 \\
Tricuspid valve insufficiency, $\mathrm{n}(\%)$ & $6(46.2)$ & $17(27.9)$ & 0.222 \\
$\quad$ Mild & $4(30.8)$ & $1(1.6)$ & 0.154 \\
Medium to severe & $2(15.4)$ & $1(1.6)$ & 0.833 \\
Pulmonary insufficiency $(m i l d), \mathrm{n}(\%)$ & $1(7.7)$ & $21(34.4)$ & 0.023 \\
Multiple valve involvement, $\mathrm{n}(\%)$ & $8(61.5)$ & $19(31.2)$ & 0.222 \\
Single valve involvement, $\mathrm{n}(\%)$ & $2(15.4)$ & & 0.069 \\
\hline
\end{tabular}

The ejection fraction was significantly lower in ASO positive group than that of normal ASO group (54.7 \pm $13.8 \%$ vs $62.4 \pm 9.2 \%, p=0.042$ ) (Table 5 ).

\section{Analysis of the risk factors of mitral and tricuspid valvular insufficiency in untreated TA patients}

We used logistic stepwise regression analysis to analyze the effects of ASO, ESR, IgA, IgG, Kerr score, ITAS, and $\mathrm{C} 3$ on mitral and tricuspid regurgitation. The results showed that the risk of mitral regurgitation in patients with elevated ASO titer was 3.9 times higher than that in patients with normal ASO ( $p=$ $0.053, \mathrm{OR}=3.929,95 \% \mathrm{CI}: 0.983-15.694)$. The risk of moderate to severe mitral regurgitation in patients with positive ASO was 41.6 times higher than that in patients with normal ASO $(p=0.002, \mathrm{OR}=41.600$, 95\% CI: 3.867-447.559).

\section{Discussion}

This study compared the clinical manifestations, laboratory findings, and heart valve disease characteristics of untreated TA patients with or without elevated ASO. We report, for the first time, that the proportion of mitral insufficiency is closely related with elevated ASO in untreated TA patients. Serum IgG was significantly higher in the ASO positive group than in the ASO negative group. In patients with positive ASO, the titer of ASO was positively correlated with ESR, IgG, and C3, and was paralleled to the TA disease activity index Kerr Score and ITAS.

Although the etiology of TA is unknown, it has long been suggested that TA pathogenesis is related to infections. Pathogen-triggered autoimmune response has also been proposed; however, convincing proof to support an association between streptococcus infection and TA is still lacking [23]. Both TA and RF could cause valvular abnormalities and present systemic clinical manifestations.

Table 5 Features of transesophageal echocardiography between the two groups in TA patients with valve involvement

\begin{tabular}{llll}
\hline Parameters & ASO positive & $n=10$ & \multicolumn{2}{c}{$\begin{array}{l}\text { ASO negative } \\
n=40\end{array}$} \\
\hline Valvular prolapse, $\mathrm{n}(\%)$ & $1(10.0)$ & $3(7.5)$ & 0.794 \\
Valvular thickening, $\mathrm{n}(\%)$ & $5(50.0)$ & $4(10.0)$ & 0.003 \\
Valvular contracture, $\mathrm{n}(\%)$ & $0(0.0)$ & $1(2.5)$ & - \\
Left ventricular end-diastolic dimension, (mm) & $52.7 \pm 12.5$ & $47.7 \pm 5.9$ & $0.05 \pm 9.2$ \\
Ejection fraction, (\%) & $54.7 \pm 13.8$ & $14(35.0)$ & 0.042 \\
Left atrium enlargement, $\mathrm{n}(\%)$ & $3(30.0)$ & $19(47.5)$ & 0.765 \\
Left ventricular diastolic dysfunction, $\mathrm{n}(\%)$ & $2(20.0)$ & $3(7.5)$ & 0.115 \\
Pulmonary hypertension, $\mathrm{n}(\%)$ & $3(30.0)$ & & 0.050 \\
\hline
\end{tabular}


Similar to our study, the association between an elevated ASO titer and TA has been described previously, with $19 \%$ of patients exhibiting an ASO titer twice the upper limit of normal [24]. Gan-gahanumaiah et al. reported a case of a female TA patient aged 29 years with heart failure, with a past history of RF, whose echocardiography suggested mitral and aortic regurgitation, and pulmonary hypertension [25]. Another case reported an 11-year-old boy with a markedly elevated ASO titer, who was initially diagnosed with acute RF; however, after admission, aortic wall thickening and enhancement were found on magnetic resonance angiography images, leading to a diagnosis of TA [7].

A previous study retrospectively assessed cardiac valvular structural abnormalities and dysfunctions and found that valvular involvement is common in TA patients, with the female to male ratio being nearly 5:1, similar to our result of 4.3:1 [26]. Aortic insufficiency was the most common finding in TA patients, followed by mitral insufficiency [12, 27, 28]. In this study, mitral insufficiency and aortic insufficiency were observed in 69.23 and $46.15 \%$ of TA patients with elevated ASO, respectively; therefore, mitral valve involvement was more likely in TA patients with elevated ASO. As shown in Fig. 1, a 32-year-old TA patient with elevated ASO, two - dimensional echocardiography suggested mitral valve calcification and prolapse, and Color Doppler ultrasound detected a large number of regurgitation signals in the left atrium. Moderate and severe mitral valve involvement was significantly more common in patients with ASO positive titers than in patients with normal ASO titers. Moderate and severe tricuspid insufficiency in TA patients with elevated ASO titers was also more frequent than that in those with normal ASO titers. Jing Li [12] reported that valvular abnormalities were found in $81.7 \%$ of TA patients, including single valve involvement in $67.2 \%$ and multiple valve involvement in $32.8 \%$. In contrast, our study found that patients with elevated ASO, $61.5 \%$ of the TA patients exhibited multiple valvular lesions compared to $15.4 \%$ of patients with single valve involvement. These results suggest that streptococcus may aggravate valve damage in patients with TA. The remodeling of cardiac chambers may implicate the adjacent atrioventricular valves destroying the structure and function, resulting in dilatation of the valvular annulus and contortion of the subvalvular apparatus. This process may deteriorate heart failure, leading to severer manifestations and poorer prognosis [29], which is the main reason for mortality in TA patients [30]. According to our data, patients with valve problems may have lower EF, and that this would be a vicious circle between more severe valve problems and heart failure.

Streptococcus pyogenes activates both the innate and adaptive immune reactions. Multiple immune cells are involved including neutrophils, lymphocytes, monocytes, and macrophages. Several immune-mediated injury mechanisms are involved in valvular damage. Similar to the pathogenesis of rheumatic heart disease, peptides derived from cardiac endothelial cells in susceptible individuals resembled the epitopes of Streptococcus, and became self-antigens by this "molecular mimicry" phenomenon. The initial event was the recognition of self-antigens on antigen presenter cells, producing autoantibodies and autoreactive $T$ cells that react against the patient's self-antigens.

Autoantibodies activated endothelial cells, and promoted vascular cell adhesion molecule 1 expression. The following process was $\mathrm{T}$-lymphocyte infiltration in the avascular valve matrix, resulting Th1-cytokine-mediated immune injuries. Furthermore, by epitope spreading, other valvular self-antigens including vimentin and collagen can be recognized and the immune response, amplified. Additionally, patients with group A streptococcal infections have elevated numbers of Th17 cells and higher serum IL-17 concentrations, indicating that Th17 responses occur in RF. These autoimmune responses were considered in association with TA [31, 32].

Recent studies have found that recombinant human $\alpha$ enolase specific positive signals were detected in 57.1\% of TA patients and specific streptococcal $\alpha$-enolase
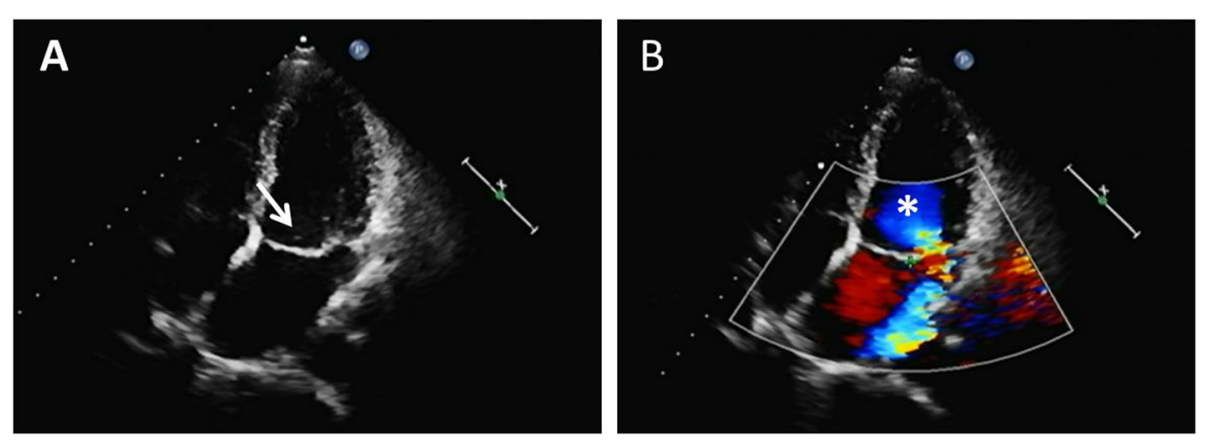

Fig. 1 Echocardiography shows moderate mitral insufficiency in a 32-year-old TA patient with elevated ASO. Two - dimensional echocardiography suggested mitral valve calcification and prolapse (a), and Color Doppler ultrasound detected a large number of regurgitation signals in left atrium (b) 
positive signals were detected in 14.3\%TA patients [6]. Streptococcal M protein binding to type IV collagen in the basement membrane can induce inflammation and fibrosis of valvular cusps [33]. Carbohydrate antigen (Nacetyl $\beta$-D-glucosamine) and Group A streptococcus $M$ protein are believed to share the same epitope with human myosin and cardiac valve laminin; this structural similarity may result in antibody-mediated valve structure damage [34]. It was found that there was a large number of peripheral B-cells of active TA patients, and there were $\mathrm{CD} 20+\mathrm{B}$ cells surrounding the granulomatous lesions [35]. Accordingly, it has been reported that the serum levels of antibodies that react with selfendothelial cells are elevated in TA patients. In vitro experiments verified that the autoantibodies induced endothelial cell proliferation through the mammalian target of rapamycin (mTOR) pathway [36]. We found that the serum IgG levels were markedly higher in TA patients with elevated ASO titers than in those with negative ASO titers and had a positive correlation with the ASO titers, suggesting that autoantibodies activated by the immune response after a streptococcal infection might play an key role in valve damage.

The main limitations were the retrospective nature of this study, because TA is a rare disease. In addition, our subjects were untreated patients, so the sample size was relatively small, and most of the patients are female. This study included all patients with valvular involvement because the cause of valvular insufficiency could not be fully determined; however, we did further divide the patients into mild and moderate to severe groups.

\section{Conclusions}

In conclusion, we found that the proportion of mitral valve and tricuspid insufficiency in TA patients with elevated ASO titer was obviously higher than that in TA patients with normal ASO. ASO titer was positively correlated with IgG, ESR and C3 in TA patients with elevated ASO titer, which was parallel with the TA disease activity index. These results indicate that an elevated ASO is associated to valvular involvement in TA, which is closely related to mitral insufficiency. In TA patients with elevated ASO titer, cardiac valvular involvement should be monitored carefully.

\section{Abbreviations}

ASO: Antistreptolysin O; BMI: Body mass index; C3: Complement 3; C4: Complement 4; CRP: C-reactive protein; ESR: Erythrocyte sedimentation rate; Ig: Immunoglobulin; ITAS: Indian Takayasu clinical activity score; Kerr score: Modified version of Kerr's criteria; mTOR: Mammal targets of rapamycin; RF: Rheumatic fever; TA: Takayasu arteritis

\section{Authors' contributions}

LP conceived the study design, performed the statistical analysis, and drafted the manuscript. JD, JZ, ZQ, YR, XH and SG collected data. NG designed this study and modified the manuscript. All the other authors approved the final manuscript.

\section{Funding}

This project was supported by grants from the National Natural Science Foundation of China (91739111) and Beijing Natural Science Foundation (7184205). The sponsors did not have a role in the study design, data collection and analysis, decision to publish, or manuscript preparation.

\section{Availability of data and materials}

The datasets used and analysed during the current study are available from the corresponding author on reasonable request.

\section{Ethics approval and consent to participate}

The study was performed in accordance with the ethical principles of the Declaration of Helsinki and approved by Capital Medical University affiliated Beijing Anzhen Hospital Ethics Committee (approval number: 2018054X). Participants gave their informed consent orally to be enrolled in the study. As this study is a retrospective study, we explained to patients that the patient's clinical data have the potential to be used in future clinical studies with the support of the ethics committee, and the data used in this study was anonymised before its use.

\section{Consent for publication}

Not applicable.

\section{Competing interests}

The authors declare that they have no competing interests.

\section{Author details}

'Department of Rheumatology and Immunology, Beijing Anzhen Hospital, Capital Medical University, 2 Anzhen Road, Chaoyang District, Beijing, China. ${ }^{2}$ Department of Cardiovascular surgery, Beijing Anzhen Hospital, Capital Medical University, Beijing, China. ${ }^{3}$ Department of Cardiology, Beijing Anzhen Hospital, Capital Medical University, Beijing, China.

Received: 29 August 2019 Accepted: 28 January 2020

Published online: 03 February 2020

\section{References}

1. Onen F, Akkoc N. Epidemiology of Takayasu arteritis. Presse Med. 2017;46(7-8 Pt 2):e197-203.

2. Hotchi M. Pathological studies on Takayasu arteritis. Heart Vessels Suppl. 1992;7:11-7

3. Arnaud L, Haroche J, Mathian A, Gorochov G, Amoura Z. Pathogenesis of Takayasu's arteritis: a 2011 update. Autoimmun Rev. 2011;11(1):61-7.

4. Kim ESH, Beckman J. Takayasu arteritis: challenges in diagnosis and management. Heart. 2018;104(7):558-65.

5. Fontan PA, Pancholi V, Nociari MM, Fischetti VA. Antibodies to streptococcal surface enolase react with human alpha-enolase: implications in poststreptococcal sequelae. J Infect Dis. 2000;182(6):1712-21.

6. Cho SB, Lee JH, Ahn KJ, Cho S, Park YB, Lee SK, Bang D, Lee KH. Identification of streptococcal proteins reacting with sera from Behcet's disease and rheumatic disorders. Clin Exp Rheumatol. 2010;28(4 Suppl 60):S31-8.

7. Fein DM, Janow G, Avner JR, Fagan MJ. The heart of the matter: an atypical presentation of Takayasu arteritis in the pediatric emergency department. Pediatr Emerg Care. 2011;27(9):857-9.

8. Gormezano NW, Santos MC, Okuda EM, Catani LH, Sacchetti SB. Association between rheumatic fever and Takayasu's arteritis - case report. Rev Bras Reumatol Engl Ed. 2016;56(2):178-80.

9. Vale TC, Maciel RO, Maia D, Beato R, Cardoso F. Takayasu's Arteritis in a Patient with Sydenham's Chorea: is There an Association? Tremor Other Hyperkinet Mov (N Y). 2012;2. https://doi.org/10.7916/D8K07306. Epub 2012 Sep 12.

10. Ferreira TF, Freire M, Teodoro RB. Difficulties in the differential diagnosis between Takayasu arteritis and rheumatic fever: case report. Rev Bras Reumatol Engl Ed. 2016;56(1):90-2. 
11. Castlemain TM. Takayasu's arteritis with associated aortic insufficiency and coronary ostial obliteration. J Am Acad Nurse Pract. 2010;22(6):305-11.

12. Li J, Li H, Sun F, Chen Z, Yang Y, Zhao J, Li M, Tian X, Zeng X. Clinical characteristics of heart involvement in Chinese patients with Takayasu arteritis. J Rheumatol. 2017;44(12):1867-74.

13. Amano J, Suzuki A. Surgical treatment of cardiac involvement in Takayasu arteritis. Heart Vessels Suppl. 1992;7:168-78.

14. Matsuura K, Ogino H, Kobayashi J, Ishibashi-Ueda H, Matsuda H, Minatoya K, Sasaki H, Bando K, Niwaya K, Tagusari O, et al. Surgical treatment of aortic regurgitation due to Takayasu arteritis: long-term morbidity and mortality. Circulation. 2005;112(24):3707-12.

15. Arend WP, Michel BA, Bloch DA, Hunder GG, Calabrese LH, Edworthy SM, Fauci AS, Leavitt RY, Lie JT, Lightfoot RW Jr, et al. The American College of Rheumatology 1990 criteria for the classification of Takayasu arteritis. Arthritis Rheum. 1990:33(8):1129-34.

16. Kerr GS, Hallahan CW, Giordano J, Leavitt RY, Fauci AS, Rottem M, Hoffman GS. Takayasu arteritis. Ann Intern Med. 1994;120(11):919-29.

17. Misra R, Danda D, Rajappa SM, Ghosh A, Gupta R, Mahendranath KM, Jeyaseelan L, Lawrence A, Bacon PA. Development and initial validation of the Indian Takayasu clinical activity score (ITAS2010). Rheumatology (Oxford). 2013:52(10):1795-801.

18. Hata A, Noda M, Moriwaki R, Numano F. Angiographic findings of Takayasu arteritis: new classification. Int J Cardiol. 1996;54(Suppl):S155-63.

19. Rudski LG, Lai WW, Afilalo J, Hua L, Handschumacher MD, Chandrasekaran K, Solomon SD, Louie EK, Schiller NB. Guidelines for the echocardiographic assessment of the right heart in adults: a report from the American Society of Echocardiography endorsed by the European Association of Echocardiography, a registered branch of the European Society of Cardiology, and the Canadian Society of Echocardiography. J Am Soc Echocardiogr. 2010;23(7):685-713 quiz 786-688.

20. Lancellotti P, Tribouilloy C, Hagendorff A, Popescu BA, Edvardsen T, Pierard LA, Badano L, Zamorano JL. Recommendations for the echocardiographic assessment of native valvular regurgitation: an executive summary from the European Association of Cardiovascular Imaging. Eur Heart J Cardiovasc Imaging. 2013;14(7):611-44.

21. Quinones MA, Otto CM, Stoddard M, Waggoner A, Zoghbi WA Recommendations for quantification of Doppler echocardiography: a report from the Doppler quantification task force of the nomenclature and standards Committee of the American Society of echocardiography. J Am Soc Echocardiogr. 2002;15(2):167-84.

22. Zoghbi WA, Enriquez-Sarano M, Foster E, Grayburn PA, Kraft CD, Levine RA, Nihoyannopoulos P, Otto CM, Quinones MA, Rakowski H, et al. Recommendations for evaluation of the severity of native valvular regurgitation with two-dimensional and Doppler echocardiography. J Am Soc Echocardiogr. 2003;16(7):777-802.

23. Espinoza $J$, Ai S, Matsumura I. New Insights on the Pathogenesis of Takayasu Arteritis: Revisiting the Microbial Theory. Pathogens. 2018;7(3):73.

24. Nakao K, Ikeda M, Kimata S, Niitani H, Niyahara M. Takayasu's arteritis. Clinical report of eighty-four cases and immunological studies of seven cases. Circulation. 1967;35(6):1141-55.

25. Gangahanumaiah S, Raju V, Jayavelan RK, Kavunkal AM, Cherian VK, Danda D, Bashi W. Rare presentation of Takayasu's aortoarteritis after double valve replacement. J Thorac Cardiovasc Surg. 2008;135(2):440-1.

26. Zhang Y, Yang K, Meng X, Tian T, Fan P, Zhang H, Ma W, Song L, Wu H, Cai J, et al. Cardiac valve involvement in Takayasu arteritis is common: a retrospective study of 1,069 patients over 25 years. Am J Med Sci. 2018; 356(4):357-64

27. Lee GY, Jang SY, Ko SM, Kim EK, Lee SH, Han H, Choi SH, Kim YW, Choe YH, Kim DK. Cardiovascular manifestations of Takayasu arteritis and their relationship to the disease activity: analysis of 204 Korean patients at a single center. Int J Cardiol. 2012;159(1):14-20.

28. Soto ME, Espinola N, Flores-Suarez LF, Reyes PA. Takayasu arteritis: clinical features in 110 Mexican mestizo patients and cardiovascular impact on survival and prognosis. Clin Exp Rheumatol. 2008;26(3 Suppl 49):S9-15.

29. Lancellotti P, Dulgheru R, Marchetta S, Oury C, Garbi M. Valve disease in heart failure: secondary but not irrelevant. Heart Fail Clin. 2019;15(2):219-27.

30. Li J, Zhu M, Li M, Zheng W, Zhao J, Tian X, Zeng X. Cause of death in Chinese Takayasu arteritis patients. Medicine (Baltimore). 2016;95(27):e4069.

31. Bas HD, Baser K, Yavuz E, Bolayir HA, Yaman B, Unlu S, Cengel A, Bagriacik EU, Yalcin R. A shift in the balance of regulatory $T$ and $T$ helper 17 cells in rheumatic heart disease. J Investig Med. 2014;62(1):78-83.
32. Belizna CC, Hamidou MA, Levesque H, Guillevin L, Shoenfeld Y. Infection and vasculitis. Rheumatology (Oxford). 2009:48(5):475-82

33. Tandon R, Sharma M, Chandrashekhar Y, Kotb M, Yacoub MH, Narula J. Revisiting the pathogenesis of rheumatic fever and carditis. Nat Rev Cardiol. 2013;10(3):171-7.

34. Karthikeyan G, Guilherme L. Acute rheumatic fever. Lancet. 2018;392(10142): 161-74.

35. Stone JR, Bruneval P, Angelini A, Bartoloni G, Basso C, Batoroeva L, Buja LM, Butany J, d'Amati G, Fallon JT, et al. Consensus statement on surgical pathology of the aorta from the Society for Cardiovascular Pathology and the Association for European Cardiovascular Pathology: I. Inflammatory diseases. Cardiovasc Pathol. 2015;24(5):267-78.

36. Hadjadj J, Canaud G, Mirault T, Samson M, Bruneval P, Regent A, Goulvestre C, Witko-Sarsat V, Costedoat-Chalumeau N, Guillevin L, et al. mTOR pathway is activated in endothelial cells from patients with Takayasu arteritis and is modulated by serum immunoglobulin G. Rheumatology (Oxford). 2018; 57(6):1011-20.

\section{Publisher's Note}

Springer Nature remains neutral with regard to jurisdictional claims in published maps and institutional affiliations.
Ready to submit your research? Choose BMC and benefit from:

- fast, convenient online submission

- thorough peer review by experienced researchers in your field

- rapid publication on acceptance

- support for research data, including large and complex data types

- gold Open Access which fosters wider collaboration and increased citations

- maximum visibility for your research: over $100 \mathrm{M}$ website views per year

At $\mathrm{BMC}$, research is always in progress.

Learn more biomedcentral.com/submissions 